\title{
Cardiac manifestations of acute carbamate and organophosphate poisoning
}

\author{
A M Saadeh, N A Farsakh, M K Al-Ali
}

\begin{abstract}
Objective-To study the frequency, extent, and pathogenesis of the cardiac complications accompanying organophosphate and carbamate poisoning.

Design-Retrospective study.

Setting-A medical intensive care unit (MICU) of a general hospital.

Subjects -46 adult patients admitted over a five year period with a diagnosis of organophosphate or carbamate poisoning. Results-Cardiac complications developed in 31 patients $(67 \%)$. These were: non-cardiogenic pulmonary oedema, 20 (43\%); cardiac arrhythmias, 11 (24\%); electrocardiographic abnormalities including prolonged Q-Tc interval, 31 (67\%); ST-T changes, 19 (41\%); and conduction defects, $4(9 \%)$. Sinus tachycardia occurred in 16 patients $(35 \%)$ and sinus bradycardia in 13 (28\%). Hypertension developed in 10 patients (22\%) and hypotension in eight (17\%). Eight patients (17\%) needed respiratory support because of respiratory depression. Although more than two thirds of the patients $(67 \%)$ had a prolonged $Q-$ Tc interval, none had polymorphic ventricular tachycardia of the torsade de pointes type. Two patients died from ventricular fibrillation, an in hospital mortality of $4 \%$.
\end{abstract}

Conclusions-Cardiac complications often accompany poisoning with these compounds, particularly during the first few hours. Hypoxaemia, acidosis, and electrolyte derangements are major predisposing factors. Intensive supportive treatment in intensive or coronary care facilities with administration of atropine in adequate doses early in the course of the illness will reduce the mortality.

(Heart 1997;77:461-464)

Princess Basma

Teaching Hospital, Faculty of Medicine, Jordan University of Science and

Technology, Irbid, Jordan

A M Saadeh

N A Farsakh

M K Al-Ali

Correspondence to: Dr Abdallah Saadeh, Associate Professor of Medicine, Department of Internal Medicine, Faculty of Medicine, Jordan University of Science and Technology, PO Box 3030, Irbid, Jordan.

Accepted for publication 6 December 1996
Keywords: organophosphate; carbamate; insecticides; pesticides

The widespread use of organophosphates and carbamates as agricultural insecticides has increased the likelihood of poisoning with these compounds. Although poisoning can result from occupational exposure or accidental ingestion, in most cases there is suicidal intent, particularly in developing countries where the highest incidence of morbidity and mortality from this cause occurs. ${ }^{1}$

Cardiac complications often accompany poisoning with these compounds, which may be serious and often fatal. These complications are potentially preventable if they are recognised early and treated adequately. The extent, frequency, and pathogenesis of the cardiac toxicity from these compounds has not been clearly defined.

The current body of knowledge largely consists of limited studies and case reports. ${ }^{2-6}$ Therefore many physicians may not be fully aware of the complications. In this study we report our experience with 46 adult patients after acute intoxication with these compounds.

\section{Methods}

Over a five year period (January 1990 to January 1995) 47 patients with organophosphate or carbamate poisoning were admitted to the medical intensive care unit (MICU) of Princess Basma Teaching Hospital, North Jordan. Only 46 were included in the study. One case was excluded because of a past cardiac history. Patients were admitted to the MICU either directly from the emergency department or as later transfers from general medical wards.

Resources for estimation of blood cholinesterase activity were not available. Therefore, the diagnosis of organophosphate or carbamate poisoning depended upon: (1) a history or evidence of exposure to organophosphate compounds or carbamates within the previous 24 hours; (2) characteristic manifestations of organophosphate and carbamate poisoning, including miosis, fasciculations, and excessive salivation; and (3) improvement of the signs and symptoms of organophosphate and carbamate poisoning after administration of high doses of atropine. All these criteria were required to be present in each patient to be included in the study.

Data on the age, sex, type and source of the poisonous agent, need for assisted ventilation, duration of hospital stay, and the in-hospital outcome were obtained from the case notes. Electrocardiograms were carried out twice daily on all patients during their stay in the MICU. Chest $x$ ray and estimation of serum electrolytes and cardiac enzymes (creatinine kinase (CK) and lactate dehydrogenase $(\mathrm{LDH})$ ) were routinely done on admission to the MICU. Cardiac enzyme estimations were repeated on the following two days. Blood pressure, pulse rate, and ECG recordings taken on arrival in the emergency department or in the general medical wards were selected for analysis before the start of atropine treat- 
Table 1 Age and sex distribution

\begin{tabular}{lcccl}
\hline $\begin{array}{l}\text { Age groups } \\
\text { (years) }\end{array}$ & Female & Male & Total (\%) & F:M ratio \\
\hline $15-19$ & 11 & 7 & $18(39)$ & $1 \cdot 6: 1$ \\
$20-24$ & 8 & 4 & $12(26)$ & $2: 1$ \\
$25-29$ & 4 & 5 & $9(20)$ & $0 \cdot 8: 1$ \\
30 and over & 1 & 6 & $7(15)$ & $0 \cdot 17: 1$ \\
Total & 24 & 22 & $46(100)$ & $1 \cdot 1: 1$ \\
\hline
\end{tabular}

Table 2 Type of poisonous agent*

\begin{tabular}{lccc}
\hline Type & Females & Males & Total (\%) \\
\hline Carbamates & & & \\
$\quad$ Methomyl carbamate & 13 & 7 & 20 \\
Carbaryl carbamate & 4 & 3 & 7 \\
$\quad$ Bendiocarb carbamate & 2 & 13 & $32(70)$ \\
Total & 19 & 4 & 6 \\
Organophosphates & 2 & 1 & 2 \\
$\quad$ Dichlorvos & 1 & 2 & 2 \\
Quinalphos & - & 2 & 2 \\
Diazinon & - & 9 & $12(26)$ \\
Dimethoate & 3 & & \\
Total & & & \\
\hline
\end{tabular}

^ The type of poisonous agent was unidentified in two females (4\%).

ment. ECG analysis included the rate, rhythm, ST/T abnormalities, conduction defects, and measurement of P-R and Q-T intervals. The Q-T interval was corrected $(\mathrm{Q}-$ Tc) according to the formula of Bazett. ${ }^{7}$

Data are expressed as mean (SD). The Student $t$ test was used to determine significance. Results with $\mathrm{P}<0.05$ were considered statistically significant.

\section{Results}

Forty six case records (24 females and 22 males) were reviewed. The mean age was $23.95(9.2)$ years. There was no significant difference in the mean age between males, 26 (10) years, and females, 22 (8) years ( $P=$ 0.07 ). Table 1 gives the age and sex distribution patterns of the patients and table 2 shows the type of poisonous agents.

The major cause of poisoning was suicidal intention $(67 \%)$, followed by accidental ingestion $(24 \%)$; only $9 \%$ were due to occupational exposure. Electrocardiographic and other cardiac manifestations are presented in table 3. This table refers only to the manifestations recorded before the administration of atropine. Thirty one patients (13 males and 18 females) had a prolonged Q-Tc interval $(0.47$ $(0.05) \mathrm{s})$ with no significant difference between the males $(0.48(0.08) \mathrm{s})$ and females $(0.47(0.03) \mathrm{s})(\mathrm{P}=0.23)$. Prolongation of

Table 3 Cardiac manifestations of acute organophosphate and carbamate poisoning

\begin{tabular}{lccc}
\hline & Female & Male & Total (\%) \\
\hline Electrocardiographic manifestations & & & \\
$\quad$ Prolonged Q-Tc interval & 18 & 13 & $31(67)$ \\
Elevated ST segment & 3 & 8 & $11(24)$ \\
Inverted T waves & 3 & 5 & $8(17)$ \\
Prolonged P-R interval & 2 & 2 & $4(9)$ \\
Atrial fibrillation & - & 4 & $4(9)$ \\
Ventricular tachycardia & 1 & 3 & $4(9)$ \\
Extrasystoles & - & 1 & $2(6)$ \\
Ventricular fibrillation & & 2 & \\
Other cardiac manifestations & 11 & & $20(43)$ \\
Pulmonary oedema & 6 & 9 & $16(35)$ \\
(noncardiogenic) & 6 & 10 & $13(28)$ \\
Sinus tachycardia & 3 & 7 & $10(22)$ \\
Sinus bradycardia & 4 & 7 & $8(17)$ \\
Hypertension & & 4 & \\
Hypotension & & & \\
\hline
\end{tabular}

the Q-Tc interval ( $\geqslant 0.42 \mathrm{~s}$ in males and $\geqslant 0.43 \mathrm{~s}$ in females) was the most common ECG abnormality (67\%), followed by sinus tachycardia (35\%). Elevation of the ST segment ( $\geqslant 2 \mathrm{~mm}$ above the isoelectric line) was seen in 11 cases $(24 \%)$. This was most striking $(\geqslant 3 \mathrm{~mm})$ in the anterior precordial leads (V2-V4). The ST segment remained elevated for two days in seven cases, three days in three cases, and five days in one case. Of these 11 cases, five were associated with raised cardiac enzymes (mean values, 516 and $782 \mathrm{IU} / 1$ for $\mathrm{CK}$ and $\mathrm{LDH}$, respectively).

$\mathrm{T}$ wave inversion was seen in eight cases $(17 \%)$ and involved the anterior leads (I, aVL, V1-V5) in three cases, the inferior (II, III, aVF) in three, and the inferolateral (II, III, aVF, V5, V6) in two. Of these, only one case had a mild increase in cardiac enzymes ( 328 and $520 \mathrm{IU} / 1$ for $\mathrm{CK}$ and $\mathrm{LDH}$, respectively). First degree heart block (P-R interval $\geqslant 0.22 \mathrm{~s}$ ) occurred in four cases $(9 \%)$. No other conduction defect was observed. Atrial fibrillation was seen in four patients, all males, and was present at the time of admission before the start of atropine treatment. Of these, three cases had acute pulmonary oedema and severe hypoxaemia, and one had ST elevation in the anterior precordial leads (V2-V4) with raised cardiac enzymes.

Ventricular premature contractions were seen in three cases $(6 \%)$ and ventricular tachycardia in four $(9 \%)$. Interestingly, none of these four patients had polymorphic ventricular tachycardia of the torsade de pointes type. Of these four cases, two had short runs which subsided after short doses of intravenous lignocaine and the other two degenerated into ventricular fibrillation leading to death despite repeated doses of lignocaine and other resuscitative measures. Both cases were males with organophosphate poisoning. Neither of these two had a prolonged Q-Tc interval.

Non-cardiogenic pulmonary oedema, shown on chest $x$ ray as fluffy infiltrates in the periphery of both lung fields with normal heart size, occurred in 20 patients $(43 \%)$. The clinical and radiological signs resolved completely in 19 patients within 24 hours with atropine treatment alone. One case required repeated doses of intravenous frusemide for 48 hours. Of these 20 patients, eight (17\%) required respiratory support because of respiratory depression. Hypertension (systolic arterial pressure $\geqslant 160 \mathrm{~mm} \mathrm{Hg}$ and/or diastolic pressure $\geqslant 95 \mathrm{~mm} \mathrm{Hg}$ ) was observed in $10(22 \%)$, and hypotension (systolic arterial pressure $\leqslant 90 \mathrm{~mm} \mathrm{Hg}$ ) occurred in eight cases $(17 \%)$. The electrocardiographic and other cardiac abnormalities all returned to normal before the patients were discharged.

\section{Discussion}

The mechanism by which organophosphates and carbamates induce cardiotoxicity is still uncertain. Ludomirsky et $a l^{5}$ described three phases of cardiac toxicity after organophosphate poisoning: phase 1 , a brief period of increased sympathetic tone; phase 2, a pro- 
longed period of parasympathetic activity; and phase 3, in which Q-T prolongation followed by torsade de pointes ventricular tachycardia and then ventricular fibrillation occur.

Both sympathetic and parasympathetic overactivity have been shown to cause myocardial damage. ${ }^{8-10}$ As early as 1974 , Yasue et al ${ }^{11}$ postulated that parasympathetic overactivity plays a major role in coronary artery spasm, and later Horio et $a l^{12}$ induced coronary artery spasm in adult humans with healthy coronary arteries after intracoronary injection of acetylcholine. In a series of 168 cases of organophosphate poisoning reported by Kiss and Fazekas, ${ }^{4}$ five had a transient picture of myocardial infarction. Diffuse myocardial damage was found at necropsy in two cases of malathion poisoning (an old generation organophosphate) ${ }^{13}$ and diffuse myocarditis has been reported after carbamate poisoning. ${ }^{6}$

In our series the majority of patients with arrhythmia (three with atrial fibrillation and two with ventricular tachycardia) had severe anoxia and pulmonary oedema on admission during the early cholinergic phase of the poisoning. Two of the four patients with atrial fibrillation had hypokalaemia and one had transient elevation of the ST segment and raised cardiac enzymes. Of the 11 patients with ST segment elevation, five had raised cardiac enzymes. These findings and the above studies suggest that the cardiac toxicity associated with organophosphate and carbamate poisoning is caused by more than one mechanism. Possible mechanisms include sympathetic and parasympathetic overactivity, hypoxaemia, acidosis, electrolyte derangements, and a direct toxic effect of the compounds on the myocardium.

Some investigators ${ }^{35}$ have described a polymorphic ventricular tachycardia of the torsade de pointes type attributed to a prolongation of the Q-Tc interval associated with organophosphate poisoning. In spite of the presence of a prolonged Q-Tc interval in the majority of our patients $(67 \%)$, none of them had this type of arrhythmia.

Hassler $e t a l^{14}$ studied the effect of an intravenous organophosphate compound (Soman) on the electrical properties of foxhound hearts. Although significant ventricular ectopic activity, idioventricular rhythm, and recurrent bouts of ventricular tachycardia occurred, torsade de pointes ventricular tachycardia was not observed.

Administration of atropine in high doses has been implicated in the development of ventricular arrhythmias. ${ }^{41516}$ In our study there was no such correlation. Lyzhnikov et $a l^{3}$ and Ludomirsky et $a l^{5}$ also found no correlation between atropine therapy and ventricular arrhythmias in organophosphate poisoning.

Hypertension and sinus tachycardia, which may be seen in organophosphate and carbamate poisoning, are nicotinic effects, while hypotension and sinus bradycardia are cholinergic manifestations. ${ }^{17}$ Although bradycardia is thought to dominate in the early cholinergic phase of the poisoning, sinus tachycardia was a more frequent finding in our study. The same observation has also been made by others. ${ }^{18} 19$ Some investigators consider the presence of hypertension and sinus tachycardia to be manifestations of severe poisoning. ${ }^{20}$

Hypertension was seen in $22 \%$ and sinus tachycardia in $35 \%$ in our study. Of these cases, only $21 \%$ can be considered to have had severe poisoning as indicated by death $(4 \%)$ or the need for assisted ventilation $(17 \%)$. Ninety six per cent $(44 / 46)$ of the patients recovered fully and only $4 \%$ (two cases) died. No chronic sequelae were noted. We believe that the type of poisonous agent (organophosphate versus carbamates), the severity of the poisoning, the stage at which treatment is started, and the presence or absence of MICU facilities are the main determinant factors for the hospital mortality.

In conclusion, cardiac complications associated with organophosphate and carbamate poisoning are not fully appreciated by many physicians. Most occur during the first few hours after exposure. Hypoxaemia, acidosis, and electrolyte derangements are major predisposing factors for the development of these complications. Once the condition is recognised, the patient should immediately be transferred to an intensive or coronary care unit where appropriate monitoring and resuscitative facilities are available. Intensive supportive treatment, meticulous respiratory care, and administration of atropine in adequate doses very early in the course of the illness are the keys to successful management of these cases.

We thank Dr David Todd for help with the manuscript and Mrs L Haddad for typing the manuscript.

1 Jeyaratnam J. Acute pesticide poisoning: a major global health problem. World Health Stat $Q 1990 ; 43: 139-44$

2 Lerman Y, Hirshberg A, Shteger Z. Organophosphate and carbamate pesticide poisoning: the usefulness of a com1984;6:17-26.

3 Lyzhnikov EA, Savina AS, Shepelev VM. Pathogenesis of disorders of cardiac rhythm and conductivity in acute organophosphate insecticide poisoning. Kardiologia 1975; 15:126-9.

4 Kiss Z, Fazekas T. Arrhythmias in organophosphate poisonings. Acta Cardiol 1979;34:323-30.

5 Ludomirsky A, Klein H, Sarelli P, Becker B, Hoffman S, Taitelman U, et al. Q-T prolongation and polymorphous (torsade de pointes) ventricular arrhythmias associated with organophosphorus insecticide poisoning. $A m \mathcal{f}$ with organophosphorus

6 Moola-Or P. Carbamate insecticide and myocarditis. $f$ Med Assoc Thai 1992;75:591-4.

7 Bazett HC. An analysis of the time-relationship of electrocardiograms. Heart 1920;7:353-70.

8 Weidler DJ. Myocardial damage and cardiac arrhythmias after intracranial hemorrhage: a critical review. Stroke 1974;5:759-64.

9 Hall GE, Ettinger GH, Banting FG. An experimental production of coronary thrombosis and myocardial failure. Can Med Assoc F 1936;34:9-15.

10 Manning GW, Hall GE, Banting FG. Vagus stimulation and the production of myocardial damage. Can Med Assoc ₹ 1937;37:314-8

11 Yasue $H$, Touyama $M$, Shimamoto $M$, Kato $H$, Tanaka S, Akiyama F. Role of autonomic nervous system in the Circulation 1974;50:534-9.

12 Horio $Y$, Yasue H, Rokutanda M, Nakamura N, Ogawa $H$, Takaoka K, et al. Effects of intracoronary injection of acetylcholine on coronary arterial diameter. Am $\mathcal{F}$ Cardiol 1986;57:984-9.

13 Chharba ML, Sepaha GC, Jain SR, Bhagwat RR, Khandekar JD. ECG and necropsy changes in organKhandekar JD. ECG and necropsy changes in organ-
ophosphorus compound (malathion) poisoning. Indian $\mathcal{f}$ Med Sci 1970;24:424-9.

14 Hassler CR, Moutvic RR, Stacey DB, Hagerty MP. Studies of the action of chemical agents on the heart. Final report, 1988;USAMRDC, NTIS:AD-A 209219. 
15 Durham WF, Hayes WJ. Organic phosphorus poisoning and its therapy. Arch Environ Health 1962;5:21.

16 Massumi RA, Mason DT, Amsterdam EA, DeMaria A Miller RR, Scheinman MM, et al. Ventricular fibrillation of bradycardia. $N$ Engl $₹$ Med 1972;287:336-8.

17 Lovejoy $\mathrm{FH}$, Linden $\mathrm{CH}$. Acute poison and drug overdosage. In: Harrison's principles of internal medicine, 12th

18 Hayes MM, Van der Westhuizen NG, Gelfand M. Organ- ophosphate poisoning in Rhodesia. A study of the clinical features and management of 105 patients. S Afr Med $\mathcal{F}$ 1978;54:230-4.

19 Bardin PG, Van Eeden SF, Joubert JR. Intensive care management of acute organophosphate poisoning. A 7-year experience in the Western Cape. $S$ Afr Med $\mathscr{f} 1987 ; 72$ : experienc

20 Namba T, Nolte CT, Jackrel J, Grob D. Poisoning due to organophosphate insecticides. Acute and chronic manifestations. Am f Med 1971;50:475-92. 